Revue française de la traduction

\title{
La tour de BaBulles : traduction, proximité et distance dans l'Europe contemporaine
}

Écho du Forum de la SGDL

Michael Cronin et Marie Gravey

\section{(2) OpenEdition}

Journals

Édition électronique

URL : http://journals.openedition.org/traduire/92

DOI : $10.4000 /$ traduire.92

ISSN : 2272-9992

Éditeur

Société française des traducteurs

Édition imprimée

Date de publication : 15 décembre 2011

Pagination : 80-85

ISBN : 039-773X

ISSN : 0395-773X

Référence électronique

Michael Cronin et Marie Gravey, «La tour de BaBulles : traduction, proximité et distance dans l'Europe contemporaine », Traduire [En ligne], 225 | 2011, mis en ligne le 03 février 2014, consulté le 02 mai 2019. URL : http://journals.openedition.org/traduire/92 ; DOI : 10.4000/traduire.92 


\section{La tour de BaBulles : traduction, proximité et distance dans l'Europe contemporaine}

\section{Écho du Forum de la SGDL}

Propos de Michael Cronin, Directeur du Centre d'études sur la traduction de Dublin, mis en forme par Marie Gravey

C'est par cette intervention, consacrée au statut du traducteur littéraire dans le contexte actuel, que Michael Cronin a ouvert la deuxième journée du Forum sur la traduction littéraire(1).

Selon M. Cronin, cinq grands défis se posent au traducteur pour l'avenir : I'Europe (institutionnelle), la société, l'informatique, l'éducation et les médias.

\section{Europe institutionnelle}

Cronin part du constat que la mise en place de l'Europe se fait sous forme d'intégration économique au sein de l'Espace économique européen (EEE) ; aux projets économiques est associée une vision sociale, loin d'être aboutie mais au moins débattue, mais il manque à l'Europe une vision culturelle. Or, cette dimension culturelle est indispensable à l'élaboration d'une Europe politique : si les responsables des différents États ne se comprennent pas, cela n'a rien d'étonnant puisque chacun ignore la culture de ses partenaires.

Cronin cite l'ouvrage de C. Grataloup, Faut-il penser autrement I'histoire du monde ?(2), qui pose le problème de l'intercompréhension culturelle : celle-ci suppose de décloisonner les histoires nationales, de ne pas étudier séparément les Renaissances italienne et française, par exemple. Dans ce contexte politique et culturel, Cronin souligne le rôle ambigu du traducteur, et donc l'ambivalence des réactions que suscite sa position. Historiquement, les traducteurs ont joué un rôle identitaire important, contribuant au développement des langues nationales (enrichissement du lexique, construction syntaxique) face notamment au latin. Mais le traducteur incarne dans le même temps l'ouverture sur l'extérieur, c'est celui qui regarde constamment ailleurs pour trouver

(1) Ce colloque, organisé à Paris les 25 et 26 octobre 2011 par la Société des gens de lettres (SGDL), a été enregistré. Pour écouter les différentes présentations et tables rondes, rendez-vous sur le site de la SGDL: www.sgdl.org. La publication des actes est prévue pour la fin de l'année 2011.

(2) Christian. Grataloup, Faut-il penser autrement l'histoire du monde ?, Armand Colin, 2011, 212 p. 
d'autres littératures, d'autres idées. C'est donc une figure " qu'il ne faut pas trop fréquenter " puisque c'est celui qui, tel un " agent double ", parle à la fois votre langue et celle de l'autre.

Le traducteur littéraire a été incontournable dans l'élaboration des cultures nationales (en Grande-Bretagne, culture élisabéthaine au xvie siècle, en France à l'âge classique, en Allemagne avec le romantisme) mais sa position spécifique en fait un représentant non de l'indépendance mais de l'interdépendance, ce qui le rend à la fois incontournable et, somme toute, un peu suspect.

\section{Société}

Cronin cite le sociologue Stuart Hall, qui emploie le terme de " cosmopolitisme vernaculaire " pour décrire la spécificité des sociétés actuelles par contraste avec celles des siècles passés. Alors que, jadis, les sociétés considéraient que l'altérité radicale, l'exotisme, se situait hors d'elles, dans un ailleurs lointain et coupé de leur propre réalité immédiate, quotidienne, bon nombre de sociétés actuelles sont confrontées en permanence à l'autre, à l'étranger voire à l'étrange : l'autre se rencontre au restaurant thaï où l'on fait sa pause déjeuner ; l'autre, ce sont les nombreuses langues entendues au détour d'une rue, au pub ou dans le métro, les musiques " du monde "à la radio, etc.

Les flux migratoires des dernières décennies, et la mondialisation en général, ont introduit une complexification linguistique radicale : aujourd'hui, les langues et cultures de l'Europe, ce sont aussi celles des immigrés du monde entier qui vivent sur le territoire européen.

Ce phénomène va de pair avec un autre enjeu : la question du multiculturalisme, dénoncé par d'aucuns sur notre continent. Ces derniers temps, de nombreux commentateurs invoquent même son échec. Et la traduction est considérée comme l'un des facteurs contribuant à ce phénomène qui serait en train de miner la société actuelle. II s'agit là d'un discours qui est particulièrement présent dans les médias anglo-saxons. La traduction littéraire est, elle aussi, confrontée à cette complexification, et elle pourrait par conséquent être amenée à jouer un rôle dans ce débat de société majeur.

\section{Informatique}

D'une manière générale, l'informatique pose la question de l'avenir de l'écrit et, pour le traducteur, celle de l'impact des technologies de l'information sur le devenir de son activité. Cette question se décline sous deux grands aspects : rapport à la lecture et phénomène de la bidirectionnalité de l'Internet.

Quel que soit le lecteur, lecture sur support papier et lecture à l'écran ne s'effectuent pas de la même manière. Les rythmes et processus eux-mêmes diffèrent, comme l'a montré un groupe 
de chercheurs allemands qui a travaillé récemment sur le temps passé à parcourir une page sur un écran d'ordinateur. En enregistrant les mouvements des yeux, ces chercheurs ont constaté que, pendant la lecture à l'écran, le regard balaie la page en trois temps : haut de page, milieu, puis bas de page. En moyenne, un lecteur passerait une quinzaine de secondes sur une page lue - ou, mieux, survolée - à l'écran (contre plusieurs minutes pour une page imprimée). Ces moyennes varient d'ailleurs selon les pays et les langues, les Canadiens passant ainsi en moyenne 19 secondes par page informatique, les Français 22, et les Allemands 26.

Ce nouveau mode de lecture et cette rapidité ont une conséquence importante pour les traducteurs pragmatiques, car un tel survol rapide à la recherche d'une information entraîne un nouveau rapport à l'acceptabilité des textes. Dans un rapport de consommation immédiate, " flash " pour ainsi dire, le niveau de qualité requis reste-t-il le même?

[À titre personnel, nous serions tentée de penser que, plus une information doit pouvoir être trouvée vite, plus sa formulation doit être claire, concise... et moins l'approximation est permise, mais cela mériterait d'être nuancé, étudié par type de texte...]

La littérature, quant à elle, n'est pas confrontée à ce problème. Si l'on excepte le cas particulier de la microfiction ou fiction dite "éclair(3) ", les textes littéraires restent lus pour leurs qualités stylistiques, et la qualité de travail du traducteur humain ne semble donc pas affectée dans les mêmes proportions par ces nouvelles technologies.

L'autre aspect lié à la généralisation de l'informatique, et plus particulièrement celle de I'Internet, est le phénomène de la bidirectionnalité. Le web 2.0 ou web " sémantique " a rendu possible l'interaction. Le succès des réseaux sociaux en est l'illustration la plus évidente, mais il faut citer pour les métiers de la traduction le phénomène de la traduction collaborative ou " wiki-traduction " : les internautes participent bénévolement à la traduction des différents textes. Cronin cite l'exemple des séries coréennes sous-titrées par des internautes américains. Quelle qualité en ressort? Et quelle image du métier de traducteur cela contribue-t-il à forger, même s'il est entendu que les internautes participant à de tels travaux ne sont pas des gens du métier?

Faut-il voir dans ce phénomène une chance, une occasion de diffusion pour les textes littéraires? En tant qu'Irlandais, Cronin évoque le cas des langues rares comme le gaélique, pour lesquelles les textes diffusés restent assez modestes dans un système où toute traduction est ou serait professionnelle. Faut-il au contraire voir là une pratique abusive, mettant en circulation des traductions bas de gamme, catastrophique pour la qualité des traductions - littéraires en particulier?

(3) "Flash fiction " en anglais. Comme ces noms l'indiquent, ce type de fiction se caractérise par sa brièveté extrême (moins de 1000 mots). Si la microfiction était déjà expérimentée par Kafka ou Cortazar, elle s'est particulièrement développée avec l'arrivée d'Internet. 
L'informatique pose au fond le problème de la "chronodiversité " - un thème moins connu et médiatisé que celui de la biodiversité !

Pour schématiser, on peut considérer qu'à l'époque des correspondances par voie postale, il était entendu que l'on disposait d'environ une semaine pour répondre à un courrier. Le fax a modifié la donne, le délai de réponse habituelle passant à deux jours plus ou moins. La généralisation du courrier électronique et des SMS nous impose quant à elle une réactivité de l'ordre de quelques heures voire quelques minutes.

L'époque actuelle est devenue celle du temps instantané. La Grande-Bretagne est désormais une société du 24/7 où les magasins sont ouverts en permanence. La notion sacrale du temps a disparu : il n'existe plus de temps dédié à autre chose qu'à la consommation.

Et la traduction littéraire dans ce contexte? Elle nous rappelle que différents types de temps continuent d'exister. La traduction littéraire - tout comme son apprentissage, qui prend des années - s'inscrit dans la durée. Sur ce point, le traducteur est donc confronté à un défi de taille : il s'agit pour lui de faire reconnaître que certaines activités requièrent un autre temps que celui de l'immédiateté, que tout n'est pas instantané... et que la valeur d'un travail ne réside pas dans la rapidité de sa livraison.

\section{4. Éducation}

II faut ici entendre par l'éducation non pas la formation des traducteurs, mais celle du public, lecteur de traductions. Cronin rappelle que l'Irlande a deux langues nationales, l'anglais et le gaélique. Or, les manuels de littérature ne font aucune place aux œuvres marquantes en traduction vers ces langues nationales.

Cronin cite l'exemple, dans l'Angleterre du Xvie siècle, des traductions d'Ovide réalisées par Golding, qui ont été fondamentales pour l'évolution de la langue et de la culture anglaises. Shakespeare a par exemple largement puisé dans ces traductions.

De même, la traduction de Madame Bovary par Eleanor Marx est régulièrement mentionnée par D.H. Lawrence comme étant sa "Bible ", et ce fut plus généralement une influence essentielle sur le roman anglais du xıxe siècle. Dans la même sphère culturelle, on peut aussi citer, pour la poésie anglo-américaine contemporaine, l'importance des traductions d'Ezra Pound.

Se pose donc un énorme défi éducatif, qui consisterait à amener les traductions dans les programmes scolaires. II s'agit de décloisonner, ce qui n'est pas antinomique avec une priorité donnée aux littératures " nationales ", les langues-cultures nationales s'étant sans cesse nourries des traductions d'œuvres étrangères. 


\section{Médias}

Dans La légende des anges(4), Michel Serres explique que le rôle de l'ange a ceci de spécifique que cette figure délivre son message puis disparaît. De même, le traducteur transmet le message, et s'efface.

À l'inverse, les journalistes et autres animateurs de télévision passent au premier plan, reléguant le message au rang de donnée secondaire. Sortes d'anges déchus, ces messagers des temps modernes tendent à accaparer tout l'espace médiatique. Cependant, ces mêmes messagers sont très importants pour la traduction littéraire.

En préparant il y a quelques années une étude sur la littérature dans le contexte européen(5), Cronin a constaté que les acteurs de la chaîne du livre faisaient leur travail sérieusement : les éditeurs avaient préparé les ouvrages, les traducteurs avaient traduit les œuvres, mais ces livres ne parvenaient pas au public car il n'y avait personne dans les médias pour transmettre au lecteur " la bonne parole traductive ".

II manquait un maillon fondamental : une médiation, comprise comme pont entre les littératures traduites et le public de la culture de réception. Suite à cette étude, Cronin avait proposé un système de bourses européennes qui permettrait aux journalistes et chroniqueurs littéraires de séjourner dans d'autres pays pour en découvrir, en immersion, la culture et la littérature, voire la langue. Chacun (médiateur, éditeur, lecteur) aurait en effet tout à gagner à ce que les médiateurs connaissent mieux la littérature étrangère, le contexte dans lequel s'inscrit une œuvre donnée.

Pour Cronin, puisque les anges déchus sont omniprésents, le traducteur, parmi d'autres acteurs de la vie littéraire, doit apprendre à composer avec eux, à s'en faire des alliés utiles et avertis.

Revenons maintenant - enfin ! - sur le titre de cette contribution.

M. Cronin a emprunté l'expression " tour de BaBulles » à Albertas Vidziunas, dramaturge lituanien invité dans une émission culturelle britannique (l'émission était en anglais, et Vidziunas jouait sur la paronomase "Babel " / Bubble ", que Cronin a adaptée en français). Vidziunas évoquait alors la Lituanie sous domination russe, et la tentative de la Russie d'éradiquer la langue et la culture lituaniennes. Afin de continuer à lire des ouvrages dans la langue nationale, la population avait organisé un système de passeurs de livres (opérant via la Suède notamment), lesquels passeurs étaient indispensables à la survie de la langue-culture lituanienne.

Au-delà de la paronomase, la métaphore de la bulle illustre donc la fragilité des languescultures : chacune risque l'éclatement, et c'est seulement en fusionnant avec une autre, plus

(4) Michel Serres, La Légende des anges, Flammarion, 1993, 302 p.

(5) Michael Cronin, "Bringing Europe to Book? Literature and the Promotion of Cultural Diversity in the European Union", in Translation Ireland, 2005, pp. 5-20. 
grande, qu'elle peut survivre. Cette vision est à double tranchant : s'ouvrir à l'autre, autrement dit se fondre dans une autre bulle, plus grande et plus solide, c'est aussi prendre le risque que cette dernière devienne plus grosse encore et fasse disparaître complètement la première.

Cronin voit pour sa part dans cette métaphore la possibilité pour une langue-culture de continuer à exister en allant à la rencontre d'autres langues-cultures. La " tour de Babulles » illustre ainsi la conscience de la fragilité mais aussi de la nécessité de l'ouverture sur l'autre qui, seule, peut permettre de sauvegarder la diversité.

Cette contribution de M. Cronin, qui intervenait dans un forum sur le métier de traducteur (en France et dans le monde), mais aussi sur l'économie et la géographie de la traduction, a choisi de situer le travail du traducteur littéraire dans un contexte large, global : à ses yeux, il s'agit certes pour le traducteur de ne pas rester invisible ; mais ce n'est pas - ou pas seulement à l'échelle de ses conditions de travail ou de son statut qu'il doit gagner en visibilité ; l'enjeu est pour le traducteur de mettre en évidence toute l'importance du travail de traduction, son caractère stratégique, serait-on tenté de dire. Selon Cronin, l'avenir de l'Europe, et pourquoi pas celui du monde, dépend largement des outils et conceptions que peuvent apporter les traducteurs littéraires! 